Voix et Images

\title{
Origines et destin des cultures dans l'oeuvre de Marius Barbeau
}

\section{Fernande Saint-Martin}

Volume 2, numéro 2, décembre 1976

Paul Chamberland

URI : https://id.erudit.org/iderudit/200056ar

DOI : https://doi.org/10.7202/200056ar

Aller au sommaire du numéro

Éditeur(s)

Les Presses de l'Université du Québec

ISSN

0318-9201 (imprimé)

1705-933X (numérique)

Découvrir la revue

Citer cet article

Saint-Martin, F. (1976). Origines et destin des cultures dans l'oeuvre de Marius Barbeau. Voix et Images, 2(2), 240-254. https://doi.org/10.7202/200056ar d'utilisation que vous pouvez consulter en ligne.

https://apropos.erudit.org/fr/usagers/politique-dutilisation/ 


\section{Origines et destin des cultures dans l'œuvre de Marius Barbeau}

"Nous sommes des ombres et nous nous en irons comme des ombres ", répétait volontiers Marius Barbeau.

La dimension tragique de cette déclaration enveloppe toute l'œurre de Marius Barbeau, écrivain, ethnologue, folkloriste et historien d'art qui, à la fois comme artiste et comme savant, s'est confronté aux problèmes les plus aigus qui se posent à l'homme, de quelque société qu'il soit: qui sommes-nous, d'où venons-nous, où allons-nous?

Écrivain et savant, oui, car au contraire de ce que prétendent certains préjugés superficiels, c'est bien souvent à travers des œuvres scientifiques, celles des Copernic, des Darwin, des Einstein, des Freud, qu'ont été proposées à la sensibilité humaine les intuitions les plus graves et les plus dramatiques. Déchirant les équilibres parfois illusoires des philosophes, poètes ou romanciers, les savants par un recours à d'autres aspects du réel contraignent souvent les hommes à rejeter les mythes consolateurs pour les obliger à reformer des synthèses émotives plus fécondes. Les anthropologues et ethnologues jouent encore dans nos sociétés ce rôle essentiel. L'œuvre gigantesque de Marius Barbeau a été unique au Québec, à remplir aussi bien ce rôle de ressourcement et de fondement de notre culture, que de témoin de la fragilité et de la complexité de l'évolution des hommes et des sociétés.

Peu de Canadiens français eurent une telle stature. Du moins depuis ces temps héroïques des pionniers de la Nouvelle-France, dont Marius Barbeau contempla lui-même la démesure, d'un œil à la fois passionné et serein. Ceux-ci rêvaient de façonner, pour leurs enfants, un avenir grandiose sur un continent sans bornes. Marius Barbeau rêva, à l'inverse, de réinventer pour nos enfants, un passé lourd et dense, d'une complexité dont nous avions peu à peu perdu le goût et à laquelle nous ne sommes pas encore acclimatés.

Pour les Québécois, comme pour bien d'autres sociétés, le passé représente, à divers titres, une expérience traumatique, sur laquelle on préfère le plus souvent fermer les yeux ou les détourner vers les mirages 
d'un avenir utopique. Pas plus que le présent ou le futur, le passé ne peut impunément se résumer à quelques images d'Épinal, ni se percevoir comme une belle et douloureuse histoire qui attendrait impatiemment un "happy ending", non plus que comme un livre tout simple de leçons qu'il suffirait d'appliquer aujourd'hui dans la sécurité de ce que nous pensons ou voudrions être.

Pour l'individu comme pour le groupe, le passé est justement cette composante essentielle dont l'oubli ne peut que rendre le présent opaque. Dimension inéluctable aussi, parce que nous ne pouvons faire que ce qui a été n'ait pas été. Le passé constitue cet élément de nous-même qu'il nous faut connaître et assimiler, si nous voulons percevoir notre insaisissable existentialité présente.

Par la profondeur de sa sensibilité, l'ampleur de sa vision, Barbeau fut l'un des premiers Canadiens français à circonscrire et affronter toute les ambiguïtés de notre destin. Sans doute doit-on à ses découvertes personnelles, à sa valorisation passionnée de notre folklore, ce regain de nationalisme au Québec, fondé sur une connaissance réelle des mceurs, des chansons, des musiques, des habitudes culinaires, aussi bien que des sculptures, orfèvreries, broderies et architectures, à travers lesquels se sont exprimés pendant trois siècles, de façon continue, nos ancêtres. Mais il domina aussi, d'est en ouest du pays, les recherches fondamentales sur la réalité anthropologique des anciens et nouveaux résidents de ce territoire.

Chacun de ses engagements et chacune de ses réalisations aurait facilement rempli la vie, la carrière de plusieurs autres. Auteur de près de sept cents écrits, dont plus de soixante livres, ouvrages spécialisés aussi bien que de vulgarisation, il fut le premier écrivain canadien-français intégralement bilingue, traduisant lui-même ses œuvres, écrites indifféremment dans l'une ou l'autre des deux langues du pays. Paradoxalement, Marius Barbeau remporta le premier Prix David de la province dans la section anglaise, en 1925, pour Indian Days in the Canadian Rockies, exploit qu'il renouvela en 1929, avec The Downfall of Temlaham, tout en décrochant un troisième Prix David, pour un ouvrage en langue française, en 1945, Saintes Artisanes. Un éminent critique a décrit comme «un chef d'œuvre littéraire et ethnologique " "la version française de The Downfall of Temlaham parue sous le titre de le Rêve de Kamalmouk.

Je ne voudrais m'attarder à 'énumérer tous les honneurs que l'ampleur de ses réalisations mérita à Marius Barbeau, depuis le doctorat Honoris Causa décerné par l'Université Oxford jusqu'à l'attribution de son nom au plus haut sommet de l'Arctique canadien. Les plus hauts témoins de sa gloire demeureront pourtant les admirables sculptures ou totems des Indiens de la Côte Ouest qu'il a découverts, minutieusement décrits, sauvés de l'extinction, et qui grâce à lui sont maintenant abrités dans le Musée de l'Homme à Paris, le British Museum de Londres, le musée d'Edimbourg et divers musées canadiens. 
Il n'est pas non plus de mon propos de faire cuvre d'historien ou d'ethnographe et de discuter ici le bien-fondé des multitudes d'hypothèses et de jugements offerts par Marius Barbeau, à partir de son premier dévoilement d'une documentation quasi inconnue avant lui.

Je voudrais plutôt en exposant les grandes lignes de sa démarche proposer une tentative d'interprétation de sa pensée, des grands thèmes qui sous-tendent ses travaux, ses recherches, ses découvertes ellesmêmes. Ils portent essentiellement selon nous, sur une interrogation profonde de la notion de culture elle-même, sur l'origine des cultures, leur développement, leur destin ultime.

Pour entrevoir, en effet, le sens de la passion dominante qui pourra seule le rendre capable d'une cuvre aussi gigantesque, il faut revenir au rêve qu'entretenait le jeune étudiant en droit de l'Université Laval et qu'il confiait à son condisciple, Louis Saint-Laurent: «Nous avons beaucoup parlé ensemble», raconte Marius Barbeau. "Je l'ai souvent scandalisé par ce qu'il appelait mes idées de libre-penseur. Un jour que nous discutions de nos projets d'avenir, je lui dis que j'aimerais découvrir comment l'homme avait été créé. Comment était l'homme au sortir des mains du Créateur, quelle était la nature de l'homme avant les interférences de l'histoire et de la société? "

Cette recherche est aujourd'hui beaucoup plus celle de l'artiste que du savant, de l'artiste qui se voue à retrouver les sources les plus originales et fondamentales de l'homme, s'émerveillant des harmonies originelles qu'il met à jour. Un artiste, c'est ce que demeurera toujours l'anthropologue et historien d'art Marius Barbeau, capable de percevoir et de décrire avec une justesse inégalée, les innombrables objets d'art qu'il a tirés de l'obscurité du passé. Qu'on songe seulement à la trajectoire parcourue depuis la thèse de doctorat en anthropologie à Oxford, portant sur le Système totémique des tribus du Nord-Ouest de l'Amérique du Nord à l'avertissement qui précède le magistral ouvrage sur les sculptures représentant les "Medecine-Men", produites par les Indiens Haida, et qui spécifie que son but est de les étudier «du point de vue des arts plastiques $^{2}$ ". II réussit admirablement à faire ressortir les éléments significatifs dans le rythme des formes, la souplesse des arabesques, les oppositions de graphismes et de textures.

Néanmoins il est certain que les études du jeune ethnologue à $O x-$ ford et à la Sorbonne, lui firent sentir le caractère utopique de son rêve de jeunesse. Non seulement la nature de l'homme, à son origine, perdue dans les brumes du temps, ne pouvait être l'objet d'une recherche réelle. Mais l'ethnographie devait lui dévoiler l'impossibilité de jamais découvrir l'homme à l'état de nature, c'est-à-dire qui ne serait pas inséré dans une culture qu'il transforme sans cesse, en même temps qu'il est conditionné par elle.

Dès lors se formulera pour Marius Barbeau la question fondamentale: comment naissent les cultures humaines, comment s'épanouissent- 
elles, quels facteurs les font durer, puis décliner, pour s'évanouir à jamais ou renaître dynamiquement peut-être?

Aux yeux de Marius Barbeau, le terme de "culture" recouvre une réalité extrêmement vaste. Et en ce sens, il fut innovateur dans notre milieu. Pour lui, la culture, c'est aussi bien la façon de manger, de s'amuser, de se loger, de chanter, de soulever son chapeau «lorsqu'on croise un étranger"; c'est aussi sûrement un terme qui recouvre les modes d'expression les plus hauts et les plus valables de divers groupes sociaux. La culture serait donc l'ensemble des formes qui permettent à un groupe social de se différencier, de s'exprimer et de s'épanouir dans l'univers humain qu'il façonne autour de lui et qui reflètent les forces de vie créatrice que secrète ce groupe.

Les interrogations de Marius Barbeau sont celles qui tourmentent encore aujourd'hui la collectivité québécoise. Comment peut-on déterminer les paramètres sociaux q'ii vont permettre ou non à un peuple de s'affirmer pleinement, dans sa propre réalité? Ce mouvement créateur qui porte un peuple au sommet de lui-même, d'où est-il issu? "Vient-il de l'isolement, se demande Barbeau, de la tradition, ou de la prospérité et du patronage. Autrement dit, les arts naissent-ils d'eux-mêmes, sont-ils empruntés, ou sont-ils les fruits du loisir et de la richesse ${ }^{3}$ ?"

La réponse apportée par Barbeau à ces questions, à partir des trois cultures qu'il a étudiées, la culture des Indiens de la Côte Ouest du Pacifique, celle des Indiens Hurons dans l'Est et celle des Canadiens français jusqu'au début du $X X^{e}$ siècle, constitue la base du très important message qu'il nous a laissé, message positif et optimiste par certains côtés, douloureux et révoltant par d'autres, nous obligeant, de toute façon, à reviser la plupart des clichés qui sont encore à l'honneur parmi ceux qui sont plus soucieux de démagogie que de fonder véritablement les espoirs humains de s'épanouir et d'être fructueux.

L'on sait que de 1915 à 1939, après son entrée au Musée national à Ottawa, Marius Barbeau décida de vérifier sur place, c'est-à-dire sur les territoires mêmes des Indiens de la Côte Nord du Pacifique et des Esquimaux d'Alaska, les thèmes ethnologiques explorés pendant ses études. Par là, l'anthropologie entrait dans la culture canadienne, de langue française comme de langue anglaise.

De multiples facteurs: persistance dans la langue et dans le rythme des chansons d'éléments phonétiques hindous et chinois ${ }^{4}$, l'utilisation dans la sculpture du chapeau mongolien, l'usage des canots jumelés nés sur la Côte Est de l'Asie, lui firent accepter d'emblée pour expliquer les origines des Indiens d'Amérique, l'hypothèse du "diffusionnisme" proposée par Franz Boas, le père de l'anthropologie moderne, voulant qu'une multitude de faits culturels similaires puissent s'expliquer par l'existence d'une souche originale commune. II s'agirait chez les Indiens d'une source asiatique qui essaima sur les deux Amériques. Difficile à vérifier, lorsque cette diffusion eut lieu il y a plus d'un millénaire, cette 
hypothèse offre un cadre particulièrement fructueux pour expliquer des développements culturels plus récents, et même contemporains.

A travers ses analyses des cuvres indiennes parlées, chantées ou sculptées, Barbeau maintiendra toujours en arrière-fond, cette vision tragique de l'Indien du Pacifique comme l'exilé douloureux, repoussé par les hordes de Gengis Khan loin de sa culture d'origine, dépossédé d'une haute civilisation, rétrogradant en terre d'Amérique de l'âge de bronze aux rudiments de l'âge de pierre ${ }^{5}$, mais toujours nostalgique de sa grandeur passée, que lui redisent encore par bribes, ses chants et ses légendes.

Ces peuples donc, coupés de leurs origines sauf pour le passage possible de missionnaires bouddhistes au $\mathrm{V}^{\mathbf{e}}$ siècle ${ }^{6}$ connaissent soudain vers la moitié $\mathrm{du} \mathrm{XIX}^{\mathrm{e}}$ siècle, un épanouissement artistique incomparable, qui rendra à jamais leur existence un fait de culture riche et plein pour les autres hommes.

L'on imagine l'émerveillement d'un jeune ethnologue auquel il est donné de découvrir et d'observer l'émergence inattendue d'un art de haute culture, datant d'à peine cinquante ans et qui déroule ses derniers feux devant lui. II suscita chez Barbeau d'innombrables questions et des réponses appuyées sur la réalité elle-même.

D'une part, Marius Barbeau découvre et affirme, à juste titre, la grandeur de cet art. II écrit en exergue à son ouvrage sur l'œuvre des artistes originaires de la Côte Nord du Pacifique:

Leur génie a produit des cuvres d'art monumentales égales aux plus originales que le monde ait jamais connues [...]

Indépendants de nos grands artistes modernes, de Turner à Gauguin, Van Gogh et Cézanne, ils furent néanmoins leurs contemporains ${ }^{7}$.

Comment donc s'est produite cette émergence culturelle? Car il s'agit bien d'une émergence. L'art des sculpteurs d'argillite et des totems en bois ne remonte guère aux temps préhistoriques. Les sculptures d'argillite datent au plus de 1820 et les totems ont été produits entre 1860 et 1890. Dans un vaste ouvrage, Barbeau recensa et décrivit tous les totems connus, même ceux qui étaient déjà disparus de son temps ${ }^{8}$. Sculptés dans un médium modeste, qui était depuis toujours à la portée des habitants d'Amérique, soit les hauts arbres de nos forêts, les totems sont très fragiles, ne pouvant rester debout plus de cinquante à soixante ans dans la splendeur de leur élan et de leur haute coloration rouge, noire et verte, à cause de l'humidité du climat?. Ne parviendront à la postérité véritablement que ceux dont la permanence est assurée par la protection des grands musées du monde.

La grandeur de cet art ne tient-elle pas, comme dans la plupart des cultures primitives, à ce qu'il soit lié à une fonction religieuse? Pas spécifiquement cette fois. Ces sculptures en argillite ou les totems de bois ne représentaient pas des "dieux païens" ni des démons, comme l'ont cru les missionnaires chrétiens, arrivés en ces régions aux environs de 1880 . Elles ne furent jamais adorées et ne servirent pas comme objets de culte. 
Du moins ces «totems" ne symbolisaient-ils pas les structures profondes de toute l'organisation sociale et culturelle, comme cela fut le cas pour d'autres produits similaires étudiés par l'ethnologie. Justement ce terme avec lequel on les désigne est extrêmement impropre. Car si Barbeau a pu observé que ces groupes d'Indiens ont conservé l'organisation sociale transmise par les premiers ancêtres d'Alaska, venus de la Sibérie, comportant le village à deux clans, les phratries et l'exogamie, les lignées matrilinéaires, ils ne sont pas des sociétés "totémistes" en tant que telles. Et l'organisation formelle de leur art est plutôt dérivée de certains systèmes décoratifs européens:

"Ce qu'on a appelé le système totémique de la Côte Nord du Pacifique est le nourrisson du système héraldique européen, qui présenta très tôt un attrait puissant aux indigènes américains et que s'approprièrent, avec ou sans permission, les intermédiaires indigènes engagés dans le commerce de la fourrure ${ }^{10}$." Le symbole de l'Oiseau-Tonnerre, thème d'origine asiatique, dont Barbeau dit qu'il fut la première matrice à partir de laquelle l'art des totems se développa rapidement, était un emprunt à l'image de l'aigle impérial russe à deux têtes, introduite en Alaska par les Russes après 1741 , symbole qui se solidifia ensuite du soutien subséquent de l'aigle américain lui-même.

Plus paradoxal encore dans cet art à fondement animiste sera l'usage important qu'on y fait du symbole de la Grenouille ou de la Mère Grenouille, alors que précise Barbeau, cet animal était inexistant et inconnu sur la Côte Nord du Pacifique ou aux îles de la Reine Charlotte. Ce symbole de la Grenouille aurait été transmis de la lointaine Asie centrale, sous forme d'amulette, du vieux monde dans le nouveau.

Qu'importe peut-être un système symbolique visuel emprunté et ensuite valorisé de façon différente, du moins le contenu même des légendes illustrées appartenait en propre au groupe humain qui le porta au plus haut niveau d'expression. Si les Haida furent les plus grands artistes "totémistes", métamorphosant leurs villages, au rythme de deux totems par maison, en un panorama fantastique de gratte-ciel, formés de cinq cents hauts et fiers totems ${ }^{11}$, ils illustraient cependant des légendes qui ne leur appartenaient pas. Ils ne les ont guère inventées, mais tout bonnement empruntées à leurs voisins du Nord et de l'Est, particulièrement aux Tsimsyans, quand le besoin de sujets artistiques nouveaux se fit sérieusement sentir. S'ils rendirent hautement visuels ces thèmes légendaires, ils n'apportèrent pas de transformations notables à leur contenu original ${ }^{12}$.

Barbeau a consacré des efforts extraordinaires à recueillir ces légendes, des Indiens dont il avait appris la langue, à les relater et à noter leurs innombrables variantes, véhiculées dans les œuvres d'art, comme dans les chants, danses et costumes. Son analyse du thème de la MèreOurs, par exemple, souligne la permanence et la similarité foncière des grands archétypes, qui, dans un grand nombre de cultures ne disent 
pas comment était l'homme au moment où il fut créé, tentent cependant de dire comment il est apparu. Soit par l'union mystique d'une divinité avec un être humain pour procréer un enfant, partageant les caractéristiques surnaturelles et naturelles des parents, devenant un intermédiaire entre ces deux mondes, le sacrifice et l'immolation d'un être surnaturel pour le salut d'un clan, d'une tribu ou de I'humanité; la communion collective, après la cérémonie de purification, par l'absorption de la chair de l'être surnaturel immolé, les rites de réparation, d'offrande et de prières adressés par la société naturelle aux pouvoirs surnaturels, etc. ${ }^{13}$.

Si elle surgit d'un fond commun, pour être grande et originale, une expression culturelle ne doit-elle pas du moins se constituer à partir de techniques, sinon inventées, du moins longuement adaptées et transformées par l'inventivité propre d'un groupe humain?

Comme au niveau de la forme et du contenu symbolique, les techniques de réalisation de l'art des totems, issu des sculptures d'argillite, sont aussi le fruit d'emprunts radicaux, très récents, à des cultures étrangères. C'est vers 1820 que les Indiens, chasseurs et pêcheurs, embauchés sur les baleiniers américains, se prirent à imiter les petits objets que sculptaient dans les os de baleine, les matelots blancs pendant leurs heures de loisir. Ils s'initièrent ainsi à un type de sculpture qu'ils n'avaient jamais pratiqué dans le passé et pendant longtemps répétèrent les images stéréotypées produites par ces Blancs, jusqu'à ce que le succès commercial inouï remporté par la vente de ces petits objets, les poussèrent à explorer un symbolisme plus vaste, issu cette fois des légendes indiennes.

Nous sommes donc en présence du développement accéléré d'un art qui emprunte ses techniques et ses formes à des cultures étrangères, mais qui en les appliquant à des matières différentes, surpassera celui des maîtres blancs dans une expression qui deviendra authentiquement la leur. «Rejetant les entraves des liens étrangers, il adopta l'argillite et le bois comme media préférés d'expression plastique et choisit d'illustrer ses contes indigènes et sa mythologie. Dans ce champ vierge, il s'est immortalisé aux plus hauts niveaux de l'art universel ${ }^{14}$."

L'art des totems, sauf pour l'apprentissage qu'a constitué la sculpture d'argillite, puisque ce sont les mêmes artistes qui réalisèrent ces deux types d'œuvres, et leur lointaine parenté avec les "house-posts" du XVIII siècle, n'a même pas connu le rythme d'une évolution et d'un perfectionnement graduel. Dès les premiers produits, les totems sont apparus dans toute leur splendeur et demeurèrent tels quels, présentant les mêmes caractéristiques, sans variations majeures entre 1840 et $1890^{15}$.

Faudra-t-il encore pour comprendre les fondements de cette explosion culturelle y voir le fruit d'un grand mouvement de la créativité et de la participation populaire, comme nous disons aujourd'hui. Sans doute a-t-il fallu la complicité, ou du moins l'obéissance, des membres du clan pour défrayer le coût de fabrication de l'un ou l'autre de ces totems, mis en chantier par les familles du chef et qui absorbaient les ressources presque 
totales d'une famille ou d'un clan. En 1899, par exemple, un sculpteur reçut l'équivalent de mille cinquante dollars de l'argent de l'époque pour avoir sculpté l'un d'entre eux et un autre sculpteur reçut l'équivalent de mille trente-six dollars sans compter les frais de matériaux et l'aide manuelle requise ${ }^{16}$. Ces artistes étaient des professionnels, choisis parmi les neveux du chef, formés depuis l'enfance exclusivement à l'exécution de leur art. Ces artistes peu nombreux, dont les noms nous sont d'ailleurs connus, qui écartaient sous peine de mort les curieux qui osaient jeter un regard sur le processus de réalisation de l'œuvre, recevaient proportionnellement davantage que ce que nos sociétés si évoluées n'accordent qu'en maugréant aux artistes actuels.

Les facteurs principaux qui entourèrent l'émergence de ces hautes formes culturelles sont d'abord et avant tout les phénomènes de l' "interaction culturelle" (le «cross-fertilization") et le regroupement inespéré de certains facteurs matériels et économiques: prospérité temporaire apportée par le commerce des fourrures, possibilité d'un marché hors de la tribu, l'apport par les Blancs de nouveaux instruments plus perfectionnés, la découverte des mines d'argillite à proximité, etc., etc.

Pourquoi ces arts déclinèrent-ils au début du $x^{e}$ siècle? Sans en énumérer les causes, Barbeau en souligne l'un des signes majeurs. Comme cela se produira selon lui, pour la culture de la Nouvelle-France, le signal de ce déclin fut l'abandon des puissants schèmes rythmiques, foncièrement abstraits, dans le traitement de la figure animale et humaine, au profit d'un réalisme banal. "Les plus jeunes générations en vinrent à un réalisme plat manquant de style et de dimension ${ }^{17}$."

C'est ce même phénomène fondamental de l'intercommunication étroite entre les diverses cultures qui frappa d'abord Barbeau dans ses recherches sur les Hurons de l'Est du pays. Le premier choc de l'ethnologue survient lorsqu'il «découvre que les Hurons de Lorette ont conservé certaines coutumes canadiennes plus fidèlement que celles de leur propre race $^{18}$ ".

II semble, en effet, que la culture des Hurons-lroquois ne s'est jamais concrétisée et épanouie dans des œuvres d'art ou des formes d'expression qui auraient pu transmettre à des contemporains ou à la postérité, quelque information sur les structures émotives particulières, les attitudes fondamentales, face au destin humain, qui structuraient leurs sociétés et leurs comportements.

C'est uniquement au contact de la culture française, souligne Barbeau, qu'on a assisté à une forme d'émergence d'une expressivité culturelle, jusque-là latente, qui trouve dans l'interaction avec les Blancs des 
possibilités d'expression qui ne franchirent pas cependant les limites d'un art sans dimensions profondes, n'accédant jamais à une véritable grandeur et originalité.

Cette influence française se fait sentir au niveau de l'expression plastique adaptée au costume et à sa décoration, ainsi que dans les contes et chants indiens.

C'est en effet une thèse majeure de Barbeau que c'est par l'intermédiaire de l'enseignement des Ursulines que les Indiens de l'Est, comme du Sud de notre pays, se formèrent à une expression plastique appliquée aux costumes, aux broderies et à une variété de bibelots d'usage domestique. Ainsi les broderies indiennes en poil d'orignal et en piquants de porc-épic ne sont guère d'origine préhistorique mais «de sources européennes ${ }^{19}$; ; les exemples les plus vieux et les plus connus n'ont même pas été produits par les Indiens. Sauf pour les Esquimaux, les Indiens "n'avaient aucune connaissance en couture... on ignorait le découpage, l'assemblage de pièces et la couture. Mais ils apprirent vite à manier ciseaux, aiguilles, alènes et fils, aussi à se vêtir à la manière des Français, dont ils convoitaient la civilisation ${ }^{20}$ ".

Cet emprunt culturel ne conduisit pas cependant à des réalisations originales, peut-être parce que le médium artistique mineur ne se prêtait pas, comme la sculpture le fit pour les Haida, à des possibilités de dépassement créateur. «L'adaptation par les sauvages des patrons déjà établis par les saintes artisanes, dans les travaux d'écorce et dans la broderie du costume, ne fut jamais vraiment créatrice ${ }^{21}$." II poursuit ailleurs: "C'est la persistance de cette forme d'artisanat et la masse des produits accumulés de toutes parts depuis 1880 , dans les musées ethnologiques d'Europe et d'Amérique, qui donnent à ce phénomène une place dans l'histoire des Peaux-Rouges 22. "Cette diffusion se fit du sud au nord, de l'est à l'ouest, précise Barbeau dans des exemples précis: "L'influence trançaise et le passage des Français se retrouvent dans les dessins géométriques des costumes des Nascopis du Labrador, qui reproduisent en les adaptant les patrons familiers des costumes français de l'époque courtoise ${ }^{23}$."

Et comme chez les Haida, les emprunts culturels des Hurons se retrouvent au sein de la tradition orale elle-même, puisque la plupart des contes et légendes recueillis chez les Indiens, note Barbeau, proviennent aussi du fond culturel français, transmis par les habitants et les coureurs de bois, 'et qui empruntent aisément le symbolisme des rois, princes et princesses, de la France d'outre-mer. Ces emprunts de contes et légendes durent jouer pourtant un rôle important dans ces sociétés indiennes, essentiellement orales, où l'art de la réthorique servait, comme chez les Grecs, de fondement aux différenciations sociales. «L'importance de l'art de dire, de chanter, de raconter tenait le premier rang dans la formation des chefs ${ }^{24}$." 
Outre les structures musicales encore peu analysées qu'utilisaient les Indiens dans les trois mille chansons enregistrées par Barbeau et qui doivent plonger dans un lointain passé asiatique, c'est finalement dans la compréhension des structures syntaxiques de la langue parlée elle-même que Barbeau décela des trésors d'expressivité qui sont inconnus à nos propres sociétés. L'un des premiers ouvrages publiés par Barbeau en 1912, traite justement d'une «classification of Iroquois radicals", à l'intérieur de ces langues syllabiques et agglutinatives. Reprenant les analyses de Franz Boas sur la structure des pronoms personnels, qu'il décrit comme "complexe, pour ne pas dire admirable", Barbeau ne cache pas sa fascination pour ces modes d'expression tellement mieux adaptés que les nôtres à une conscience réelle des relations inter-personnelles, aussi bien dans la permanence du duel que dans les catégories de pronoms personnels inclusifs et exclusifs et des pronoms composés capables de marquer toutes les modalités de la relation entre le groupe et les deux interlocuteurs privilégiés d'un dialogue.

Le drame particulier aux cultures où prédomine la tradition orale sur l'expression plastique est que leur âme et leur culture disparaissent quand les bouches elles-mêmes se ferment à jamais. Barbeau souhaite que nous prenions la relève et que nous retrouvions le sens de notre propre passé, en racontant à nos enfants, dans nos écoles, les faits héroïques des grands chefs indiens, qui ont vainement résisté à notre envahissement: les Donnaconna, Pocahontas, Dekanawida, Brant, Pontiac et Tecumseh, tous ceux qui les premiers donnèrent à ce continent une âme, avant que notre culture étouffe la leur.

C'est à une expérience émotive profonde de sa petite enfance que Marius Barbeau fait remonter la fascination qu'exerce sur lui le passé français du Québec, ce lieu historique encore obscur et indécis, mais renfermant la possibilité d'une identité spécifique.

«J'étais tout enfant lorsque, pour la première fois, je vis la vieille ville de Québec, et l'impression que j'en reçus n'est pas encore effacée... En revenant au pays, nous étions descendús du train près du vaste fleuve et nous étions montés sur un bateau dont les grandes roues, de chaque côté, battaient l'eau verdâtre, et dont la forme pansue me fit songer à une énorme grenouille...25."

Dans cette véritable naissance au pays d'origine, l'enfant Barbeau reforme instinctivement l'image mythique de la Grenouille, qu'il retrouva plus tard comme source de l'histoire humaine dans les légendes des Indiens Haida de la Côte Ouest.

L'étude ethnologique à laquelle se voue le savant Barbeau sur la société québécoise se colore cependant d'une passion et d'un ensemble de valorisations qui ne sont pas le lot habituel de la recherche scientifique, qui se voudrait objective et impersonnelle. Barbeau affirme, en effet, le caractère unique et original des structures culturelles de la société québécoise: 
«Par son histoire et sa physionomie, la province de Québec occupe une place à part en Amérique. Elle est comme un oasis au milieu du désert de l'uniformité américaine ${ }^{26}$. ”

L'étude de cette culture québécoise se pose cependant sur une double face trop souvent confondue: la première tentant d'établir les facteurs qui ont assuré sa survivance, la deuxième moins élaborée, tentant de connaître les caractéristiques mêmes de cette culture.

Barbeau explique assurément la survivance du Québec français par la force et l'autonomie qu'ont données à nos paysans la pratique des arts traditionnels, héritée de. France et poursuivie pendant près de deux cents ans jusqu'à la naissance de l'industrie moderne.

«Sans ses traditions, Québec, pas plus que la Louisianne, ne serait resté français aussi longtemps. Jusqu'à dernièrement, sa survivance dépendait du maintien de la langue, des coutumes, du folklore et des métiers populaires. " Si la survivance a failli à Détroit, Saint-Louis ou à la Nouvelle-Orléans, “c'est que les arts et métiers de l'ancienne France n'y prirent jamais racine et qu'il y manqua d'institutions civiles ou religieuses stables comme à Québec, Trois-Rivières et à Montréal ${ }^{27}$ ".

Et sans doute la disparition graduelle de ces traditions pose pour l'ethrologue une problématique réelle quant aux possibilités de survivance future de cette culture: "Le "melting-pot" américain qui produit la fusion des races mijote depuis longtemps sur les rives. fleurdelisées du Saint-Laurent ${ }^{28}$."

Mais quelles étaient les caractéristiques mêmes de cette culture et de ces traditions, qui possédèrent une force créatrice assez grande pour s'imposer dans un milieu hostile et assurer la perpétuité d'un minuscule groupe social?

Ces traditions, déclare Barbeau "se divisent en trois rameaux: la tradition intellectuelle, religieuse et littéraire, entretenue dans les séminaires, les couvents et les écoles; la tradition des arts et métiers qui se perpétuaient dans les ateliers, de maîtres à apprentis, ou simplement de père en fils, et la tradition orale, dans la masse rurale et même urbaine de la population ${ }^{29}$.

Des trois traditions fondamentales, Barbeau n'étudia que les deux dernières, soit celle des arts et métiers et la tradition orale.

D'emblée il faut poser que cette culture sur tous les plans a été dès son origine, empruntée. Dès avant 1648 , nombre de maîtres et apprentis de France s'étaient installés ici pour produire un certain nombre d'objets religieux aussi bien que domestiques essentiels, exigeant architectes, sculpteurs-ébénistes, maçons, orfèvres, etc. Ces artisans transportaient en Nouvelle-France un art issu de la Renaissance française "qui fleurit ic̣i longtemps après qu'il eût cessé d'exister en France». Parce que né et répondant à un besoin, cet artisanat fleurit et demeura vivant ${ }^{30}$. 
A ces meilleurs niveaux, cet artisanat cependant ne fut pas le fait de simples ouvriers, mais d'artisans de carrière, qui se transmirent leur art sous mode d'apprentissage, de façon continue pendant deux siècles ${ }^{31}$. Bien que les influences de l'art "vivant» en France furent très réduites, il semble que le dégagement des liens avec la métropole française, en 1760, jusqu'au moment où s'y substitueront des liens culturels efficaces avec la nouvelle métropole anglaise, accentua l'épanouissement et l'originalité d'un art devenant véritablement canadien-français ${ }^{32}$.

Liés dynamiquement au développement de la sculpture et de l'architecture religieuse, ces arts et métiers dans leur plus haute expression, n'étaient pas considérés comme des luxes inutiles par le clergé et leurs paroissiens, mais comme d'utilité. publique. Leur déclin survint accidentellement à la suite de l'introduction dans l'architecture religieuse de styles nouveaux et d'instrumentations différentes. Barbeau en date la fin symbolique dans l'érection de la cathédrale de Montréal, dans un style néo-gothique londonien, auquel les maîtres artisans ne pouvaient plus adapter leurs techniques traditionnelles et leurs conceptions stylistiques. Même l'introduction du plâtre à l'italienne, procédé plus économique et facile d'exécution, sonna le glas de la sculpture sur bois, chevillée au mur, exigeant un apprentissage plus long et poussé. A des niveaux plus modestes, tout l'artisanat subit le contre-choc de l'adoption de nouvelles techniques:

Sous l'influence nuisible de professeurs étrangers, une artisane peignit ses roses avec plus de réalisme que ne le faisaient les anciennes Mères... Le goût du réalisme dans les détails et une perte sensible du sens décoratif acheminaient à la ruine ${ }^{33}$.

C'est-à-dire que la séduction de conceptions stylistiques étrangères, le choix et le goût pour des «nouveautés», réussirent à désintégrer entièrement un édifice artistique et culturel hautement diversifié, se ramifiant dans la production des objets domestiques eux-mêmes.

Tout en affirmant la réalité et l'ampleur de la production artistique et culturelle des Canadiens français au Québec, jusqu'au milieu du XIX siècle, Barbeau conserve cependant une calme lucidité sur la portée universelle de ces faits culturels. En 1937, il écrivait: "Personne ne s'intéressait encore, il y a quinze ans, à l'histoire de l'art au Canada, bien qu'il eut là la matière à un chapitre remarquable d'histoire coloniale ${ }^{34}$. "

Qu'une culture soit coloniale, qu'elle emprunte ses lignes de force à des dónnées empruntées à des métropoles plus riches et fortes, ou même à des cultures étrangères, comme l'art des Haidà, ne sont pas des conditions qui aux yeux de l'ethnologue puissent l'empêcher d'être vivante, nécessaire, féconde et éventuellement capable d'atteindre à des sommets expressifs.

Ce paradoxe d'une culture vivante, bien qu'empruntée, nourišsant de mille façons la sensibilité et l'imaginaire d'une société, et qui demeure pourtant essentiellement statique dans ses formes et son contenu, se re- 
trouve dans l'examen du folklore oral du Québec, qui s'est maintenu parallèlement au folklore artisanal.

On sait que Barbeau y consacra ses meilleures énergies à partir de 1916, déposant par la suite au Musée national plus de treize mille textes de chansons, et sept mille mélodies. La plupart de ces œuvres, encore mémorisées au début du $x x^{\mathrm{e}}$ siècle, proviennent presque directement de la France médiévale: «Nos chansons du Québec, pour la plupart, sont sorties de France, de 1608 à 1680, ou peu après, avec les ancêtres, surtout ceux des campagnes ${ }^{35}$."

Ces chansons et légendes si populaires qui rythmaient les voyages des coureurs de bois et les soirées de village, se sont transmises au Québec sans qu'or: leur apporte de changements importants et sans donner naissance à un art original. On compte à peine une centaine de compositions du terroir dans la vaste collection recueillie par Barbeau et celles-ci, dit-il, sont «assez maladroites, car leurs compositeurs n'étaient pas des jongleurs professionnels, comme dans la France ancienne, mais de simples chanteurs rustiques ${ }^{36}$ ".

Pourtant on sent toute l'admiration que voue Barbeau à ces chanteurs et raconteuses "rustiques", capables de mémoriser deux cents ou trois cents chansons, formant dans une société orale non technologique, cette élite, cette minorité capable d'être dépositaire de la culture orale et de disséminer des faits culturels, qui sans eux se dissolveraient dans l'oubli.

Par ailleurs, il semble que le déclin que subit au milieu du $x_{1 x}{ }^{e}$ siècle l'architecture religieuse et la brisure des liens qu'elle soutenait avec les arts et métiers traditionnels, permirent à certains de ces arts de retrouver une autonomie d'orientation qui leur permettra de s'épanouir, dans un environnement profane, au $x x^{e}$ siècle, avec la vigueur que nous leur connaissons aujourd'hui. Ainsi de la peinture: "Faute d'une tradition vitale aux sources françaises, il y a plus de trois cents ans, la peinture ne prit jamais vraiment racine au Canada jusqu'à ce que, vers 1830, Antoine Plamondon, né à l'Ancienne-Lorette, se rendit en Belgique et Théophile Hamel, de Québec, en Italie, pour en apprendre les éléments ${ }^{37}$. " Et encore une fois, c'est cette même interaction entre les cultures des deux continents que Barbeau devra reconnaître, quand il présentera les pionniers de la peinture au Québec, les Suzor-Côté, Clarence Gagnon, Marc-Aurèle Fortin; Adrien Hébert, Henri Masson ou Pellan, saluant en ce dernier un dépassement de l'art du réalisme, permettant l'élaboration d'un art abstrait capable d'agir aussi bien sur' l'esprit que sur les réactions émotives les plus proforides de l'être humain ${ }^{38}$.

Comme la vie elle-même qui est essentiellement échange, la vie culturelle regroupe donc aux yeux de l'ethnologue une multitude de facteurs dynamiques provenant de filiations et d'interactions continues entre une communauté et des cultures différentes. En voulant lui-même se définir par rapport aux sources culturelles amérindiennes et européennes qui ont 
fait notre pays, Marius Barbeau a particulièrement senti le tragique de cette situation, où nous sommes ignorants des facteurs anciens qu'il faudrait perpétuer, des facteurs de "nouveauté " qu'il faudrait assimiler, l'un ou l'autre choix pouvant conduire aussi bien à la destruction des capacités créatrices qu'à leur donner un éclat jamais connu auparavant.

Dans un livre admirable, le Rêve de Kamalmouk, où il a mis beaucoup de lui-même, de «son intuition» dit-il, Marius Barbeau a reconstitué ce drame d'un être et d'une société situés aux confluents de grandes mutations culturelles. Séduit en effet par l'ampleur de la civilisation des Blancs, Kamalmouk doit renoncer pour elle aux coutumes et aux rites ancestraux.

Le parallèle est facile à tracer avec la problématique de ce Québec qui a déjà renoncé dans une grande mesure à sa société traditionnelle, pour tenter de s'intégrer aux sociétés post-industrielles, dont les valeurs semblent s'être imposées à lui. En choisissant finalement, contre la «loi des Blancs", d'avoir recours à la violence individuelle que justifiaient les coutumes anciennes, Kamalmouk consommait sa propre destruction, au sein d'un groupe devenu lui aussi incertain de ses valeurs.

Dans l'ambivalence de la société québécoise actuelle, sa difficulté de s'affirmer dans une fidélité à ses coutumes propres, mais lointaines, et la difficulté d'inventer une société sur des valeurs nouvelles, empruntées le plus souvent à d'autres cultures, Marius Barbeau nous avise cependant de l'importance qu'il faut accorder aux individus créateurs parmi nous, capables de donner forme aux courants les plus profonds de notre sensibilité.

Par son courage intellectuel, par sa passion pour toutes les formes d'expression de la vie, par sa sensibilité extraordinaire aux formes visuelles et musicales, Marius Barbeau fait justement partie de ces créateurs, qui permettent éventuellement à une culture d'affirmer son identité, de s'exprimer et par là de rendre aux autres hommes ce qu'on aura reçu d'eux, mais magnifié mille fois.

Fernande Saint-Martin

\footnotetext{
1. Jean-Éthíer Blais, “Témoignage - Marius Barbeau; les accords d'une vie musicale ", le Devoir, 22 mars 1969.

2. Marius Barbeau, Medecine-Men in the North Pacific Coast, Ottawa, National Museum of Canada, Anthropological series, $n^{\sigma} 42,1958$. p. 1.

3. Id., Au cœur de Québec, Montréal. Les Éditions du Zodiaque, 1934, p. 113.

4. Id., Totem Poles. I. II. Ottawa, National Museum of Canada, Anthropological series, $n^{\circ} 30$, p. 767 .

5. Ibid.

6. Id., Comment on découvrit l'Amérique, Montréal, Librairie Beauchemin, 1966.

7. I., Alaska Beckons, Toronto, Macmillan of Canada, 1947, p. 182-201.

8. Ibid.

9. Totem Poles, I.

10. Totem Poles, ii, p. 772.
} 
11. Ibid.

12. Haida Myths, Ottawa, National Museum of Canada, 1953, p. 403.

13. Totem Poles, p. 188.

14. Haida Myths, dans l'Exergue.

15. Alaska Beckons.

16. Totem Poles, p. 673 et p. 46.

17. Haida Myths, p. 212.

18. Luc Lacourcière, "les Études de folklore français au Canada"Culture, vol. 6, $n^{\circ} 1$, mars 1945.

19. Marius Barbeau, Saintes Artisanes, tome I, Montréal, Fides, Cahiers d'art Arca, 1943 , p. 81.

20. Ibid., p. $72-73$.

21. Ibid., p. 103.

22. Id., Fameux Peaux-Rouges d'Amérique, tome II, Montréal, Librairie Beauche$\min , 1966$, p. 117.

23. Ibid.

24. Ibid., p. 54.

25. Id., Québec où survit I'ancienne France, Québec, Librairie Garneau, 1937, p. 1.

26. Ibid., p. 157.

27. Ibid., p. 168.

28. Ibid., p. 174.

29. Ibid., p. 167.

30. Id., Cahiers de l'Académie canadienne-française, $n^{\circ}$ 9, Montréal, 1965.

31. Au ccur de Québec, p. 164.

32. Québec où survit l'ancienne France, p. 167.

33. Saintes Artisanes, p. 55.

34. Québec où survit l'ancienne France, p. 79.

35. Id., Romancero du Canada, Montréal, Éditions Beauchemin, 1937, p. 14-15.

36. Cahiers de l'Académie canadienne-française, $n^{\circ} 9$, p. 118.

37. Saintes Artisanes, tome 1, p. 52.

38. Id., Painters of Quebec, Toronto. The Ryerson Press, 1946, "Canadian Arts Series", p. 42. 